\title{
Analisando o sistema educacional brasileiro com base no uso da lógica de programação no Ensino Médio
}

\author{
Natália Bernardo Nunes ${ }^{1}$; Anelise Lemke Kologeski ${ }^{1}$ \\ ${ }^{1}$ Instituto Federal de Educação, Ciência e Tecnologia do Rio Grande do Sul - Campus \\ Osório \\ nataliabernunes@gmail.com; anelise.kologeski@osorio.ifrs.edu.br
}

\begin{abstract}
Many authors indicate the inclusion of programming logic in the school as a way of contributing to the educational development of students. So, this research intends to investigate this affirmation and the impact it can bring, especially in Secondary School. For this, a bibliographic analysis was developed, looking for the improvements that occurred in related projects, as well as a field research, in order to evaluate the impact of this theme in the students' lives, according to their respective opinions.
\end{abstract}

Resumo. Muitos autores defendem a inclusão da lógica de programação na escola como meio de contribuir para o desenvolvimento educacional dos alunos. Assim, esta pesquisa visa investigar esta afirmação e o impacto que ela pode trazer, em especial no Ensino Médio. Para isso, foi realizada uma análise bibliográfica, buscando as melhorias que ocorreram em projetos relacionados, bem como uma pesquisa de campo, a fim de avaliar o impacto deste tema na vida dos estudantes, conforme suas respectivas opiniões.

\section{Introdução}

Apesar dos avanços e alcance da tecnologia, uma problemática na sociedade atual são os baixos índices educacionais em todo o país. Segundo o site Agenda 20201, uma das causas da falta de desenvolvimento educacional no estado do Rio Grande do Sul é a "Inadequação da educação escolar às exigências do século XXI", apontando que há poucos indícios de práticas inovadoras, em especial no Ensino Médio. Um dos fatores analisados nesta plataforma é o Índice de Desenvolvimento da Educação Básica $(\text { IDEB })^{2}$, que consiste em uma prova realizada para mensurar o respectivo aprendizado dos alunos em conteúdos relacionados à leitura e à resolução de problemas. As últimas 3 edições mostraram um desempenho dos estudantes abaixo do esperado, nas escolas públicas de Ensino Médio dos municípios da região em que a investigação acontece.

Muitos hábitos do dia-a-dia se relacionam cada vez mais ao uso de recursos digitais, tornando a tecnologia um assunto de interesse para a maioria das pessoas. Segundo [Sousa et. al., 2011], ela torna-se ainda mais contextualizada, já que este público considera as novas tecnologias uma realidade irretornável na vida contemporânea, enquanto que, para [Wing, 2016], o pensamento computacional se torna uma habilidade necessária para todos, não somente cientistas da computação.

\footnotetext{
${ }^{1}$ Disponível em: $<$ http://agenda2020.com.br/sinaleira/indicadores-de-educacao/>

${ }^{2}$ Disponível em: $<\underline{\text { http://portal.inep.gov.br/ideb }>}$
} 


\section{Justificativa}

De acordo com a plataforma Agenda $2030^{3}$, para assegurar a educação inclusiva e equitativa de qualidade até o ano de 2030, é necessário aumentar substancialmente o número de jovens e adultos que tenham habilidades relevantes, inclusive competências técnicas e profissionais, para emprego, trabalho decente e empreendedorismo. Logo, os alunos deveriam estar mais preparados do que estão de fato, fazendo com que esta seja uma problemática muito recorrente em todas as escolas brasileiras e sendo necessária a investigação de uma solução eficiente para amenizar este problema.

[Câmara et. al., 2016] aponta que alunos de Ensino Fundamental e Médio que possuem contato com o ensino de programação acabam desenvolvendo capacidade e competência para a resolução de problemas e para o raciocínio lógico. Logo, um possível caminho para contornar a situação, poderia ser a implementação de ações que desenvolvam o pensamento computacional e o raciocínio lógico nas escolas, junto aos estudantes, como já vem sendo feito por [Kologeski et. al., 2019] para o Ensino Fundamental, por exemplo.

\section{Objetivos}

Este trabalho visa investigar o impacto que o ensino da lógica de programação, desde cedo, pode trazer para a vida dos estudantes, avaliando a consequência disso no desempenho escolar destes alunos. Para isso, objetiva-se analisar diferentes conteúdos que possuam esta informação, dentre estatísticas que apontem resultados na inclusão desta área em escolas de Ensino Médio, depoimentos de estudantes que tiveram este contato e estudos envolvendo os locais pesquisados, a fim de investigar se estes fatores acarretam de fato no desenvolvimento escolar dos envolvidos.

Assim, a pesquisa tem o intuito de observar como as ações que promoviam a inclusão digital realizadas em todo o território nacional impactaram no desenvolvimento educacional, procurando por indicadores determinantes. Como diferencial, este trabalho mostra um estudo em busca de projetos que promovam atividades com a lógica de programação especificamente em escolas de Ensino Médio, diferente da maioria dos projetos encontrados na busca bibliográfica, que são voltados ao Ensino Fundamental e Superior.

Contudo, foi constatada a falta de depoimentos dos alunos apenas com a revisão sistemática, tornando a pesquisa bibliográfica menos eficiente do que era esperado. Por esta razão, o estudo também envolve uma escola de Ensino Médio da região da pesquisa, aplicando questionários, tentando descobrir a quantidade de alunos que possuem este contato e como a lógica de programação interferiu em suas vidas, também comparando aos dados do IDEB.

Por fim, os resultados desta pesquisa foram sintetizados de tal forma a auxiliar o corpo docente de instituições de ensino na temática trabalhada, bem como qualquer outro público interessado em aprimorar as atuais metodologias de ensino.

\footnotetext{
${ }^{3}$ Disponível em: < $<$ https://nacoesunidas.org/pos2015/agenda2030/>
} 


\section{Metodologia}

Determinou-se que seriam feitas buscas nos periódicos dos workshops do Congresso Brasileiro de Informática na Educação e do Simpósio Brasileiro de Informática na Educação ${ }^{4}$, além da Revista Novas Tecnologias na Educação da Universidade Federal do Rio Grande do $\mathrm{Sul}^{5}$. Todas as edições consideradas compreendem o período de 2015 a 2019. Uma pré-seleção dos artigos foi realizada, escolhendo-se aqueles que abordam os temas "lógica de programação", "pensamento computacional" e "raciocínio lógico" em seu título, palavras-chave e/ou em seu resumo. Após esta seleção, necessitou-se refinar a pesquisa, analisando cada trabalho em busca apenas daqueles destinados ao Ensino Médio.

Além dos artigos encontrados na pesquisa, buscou-se também por relatos feitos pelos participantes das iniciativas, com o intuito de observar sob a visão do aluno em que sentido aquele projeto contribuiu para o seu desenvolvimento escolar. Com os dados analisados, foram relacionados os projetos realizados em cada região do país, o desenvolvimento dos alunos e os indicadores dos resultados obtidos, dentre outros.

Para que a análise seja comprovada na região em que a pesquisa está sendo realizada, foram realizados questionários diretamente com os alunos, utilizando uma plataforma online, visando à economia de papel e também à garantia de que os alunos consentem em participar da pesquisa que abrange as seguintes perguntas: "Já possuiu algum contato com lógica de programação no Ensino Fundamental?"; "Já possuiu algum contato om lógica de programação no Ensino Médio?"; "Se você respondeu sim para a pergunta anterior: este contato trouxe algum impacto (decisões) na sua vida? Qual?"; "Você possui interesse em ter contato com a lógica de programação?"; "Como foi seu desempenho em Língua Portuguesa no último ano em sua vida escolar?"; "Como foi seu desempenho em Matemática no último ano em sua vida escolar?". A formulação dessas perguntas possui o objetivo de investigar se o contato com lógica de programação é, de fato, um diferencial na vida dos estudantes.

\section{Resultados e Discussão Final}

No final da busca, dos 238 artigos filtrados, apenas 49 são projetos destinados a alunos do Ensino Médio no Brasil, nos últimos anos, mostrando que ainda há muito mais para ser feito, justamente em uma faixa etária onde os estudantes estão se preparando e se qualificando para ingresso no mercado de trabalho. Além disso, houve uma dificuldade na investigação dos projetos encontrados, devido à falta de estatísticas e depoimentos em seus resultados que relacionassem de maneira explícita o impacto causado, impossibilitando dados concretos para fins de comparação. Os resultados das estatísticas variam entre $48,7 \%$ e $90,9 \%$ referentes ao aumento das notas dos participantes antes e depois das iniciativas, bem como satisfação e interesse dos participantes, dentre outros fatores. As atividades variam com a proposta e o público-alvo, mas são resumidas em aplicativos lúdicos, e oficinas de robótica ou programação.

\footnotetext{
${ }^{4}$ Disponível em: $<$ https://cbie.ceie-br.org/2019/anais.html $>$

${ }^{5}$ Disponível em: $<$ https://seer.ufrgs.br/renote $>$
} 
Ao analisar todos os projetos destinados ao Ensino Médio, foi observada a predominância de projetos na região Sul do Brasil, enquanto encontrou-se apenas um trabalho na região Centro-Oeste dentre os projetos analisados, conforme a Tabela 1.

\begin{tabular}{|c|c|c|c|c|}
\hline Região Sul & Região Nordeste & Região Norte & Região Sudeste & Região Centro-Oeste \\
\hline $39,6 \%$ & $33,3 \%$ & $12,5 \%$ & $12,5 \%$ & $2,1 \%$ \\
\hline
\end{tabular}

Tabela 1. Relação dos 49 projetos destinados ao Ensino Médio por localidade de aplicação em cada região do Brasil. Fonte: autoria própria.

Diante da Tabela 1, foi realizada uma nova investigação no IDEB: está programado para 2019 uma diferença de 0,5 entre as escolas estaduais da região do Brasil que mais possuem trabalhos publicados (Sul) e a região com apenas um trabalho publicado (Centro- Oeste), apontando uma disparidade grande entre as duas regiões, podendo-se associar o melhor desempenho da região Sul com a maior quantidade de trabalhos relacionados à da lógica de programação.

Nas entrevistas, participaram 334 alunos da instituição de Ensino Médio onde é realizada a pesquisa, obtendo os seguintes resultados: $64,1 \%$ mencionaram já ter em algum momento do Ensino Médio algum contato com a lógica de programação; 70,3\% dos alunos consideram seu desempenho "bom" ou "excelente" em Língua Portuguesa e 62,8\% afirmaram o mesmo em Matemática. Após a obtenção destes dados, foi realizada uma busca pelo IDEB desta instituição, buscando observar se os índices também coincidiam com as respostas obtidas, e encontrou-se a informação de que $o$ desenvolvimento atingido foi superior de forma considerável da média estadual e, ainda, superior ao objetivo nacional do mesmo ano.

Como continuidade, este estudo deverá ser aprofundado, desenvolvendo a investigação a fim de identificar se o contato com a lógica de programação dos estudantes tem relação direta com o desempenho escolar, além de auxiliar os estudantes brasileiros no âmbito educacional frente às tecnologias.

\section{Referências}

Câmara, F. S. S., Silva, M. A. P, Silva, R. M. B. A Lógica de Programação como ferramenta para o ensino e a aprendizagem da Matemática. Anais do II Congresso Internacional de Educação Inclusiva, Campina Grande, PB, Brasil, 2016.

Kologeski, A. L., Batista, V., Bobsin, R., Espíndola, R. W. P., Nunes, N. B., Julio, M. B., ... \& Bona, A. Tecnologia na Educação: O Pensamento Computacional e a Computação Desplugada como forma de Inclusão Digital. In: Anais dos Workshops do Congresso Brasileiro de Informática na Educação (Vol. 8, No. 1, p. 288). Brasília, DF, Brasil, 2019.

Sousa, C. A. M. Novas linguagens e sociabilidades: como uma juventude vê novas tecnologias. In: Interacções, 2011. Revista Interacções, Repositório Científico do Instituto Politécnico de Santarém. V. 7, No 17, 2011. Acesso realizado em setembro de $2019 \mathrm{em}$ https://repositorio.ipsantarem.pt/handle/10400.15/508.

Wing, J. "Pensamento computacional - Um conjunto de atitudes e habilidades que todos, não só cientistas da computação, ficaram ansiosos para aprender e usar". Revista brasileira Ensino Ciência Tecnologia, v. 9, n. 2, p. 1-10. Ponta Grossa, PR, Brasil, 2016. 